\title{
Simultaneous Determination of
}

\section{Carbamazepine and Carbamazepine- 10,11-epoxide in Different Biological Matrices by LC-MS/MS}

\author{
Dan Andonie, Zsolt Gáll, Paul Bosa, Maria Titica Dogaru, Szende Vancea \\ Faculty of Pharmacy, University of Medicine and Pharmacy, Tîrgu Mureş, Romania
}

\section{CORRESPONDENCE}

\section{Zsolt Gáll}

Str. Gheorghe Marinescu nr. 38

540139 Tîrgu Mureș, Romania

Tel: +40743703267

Fax: +40 265210407

E-mail: gall.zsolt@umftgm.ro

\section{ARTICLE HISTORY}

Received: August 12, 2017

Accepted: August 21, 2017
Dan Andonie • Str Gheorghe Marinescu nr. 38 , 540139 Tîrgu Mureș, Romania. Tel:+400265 215551 Paul Bosa • Str. Gheorghe Marinescu nr. 38, 540139 Tîrgu Mureș, Romania. Tel:+400265 215551 Maria Titica Dogaru • Str. Gheorghe Marinescu nr. 38 540139 Tîrgu Mureș, Romania. Tel:+400265 215551 Szende Vancea - Str. Gheorghe Marinescu nr. 38 540139 Tîrgu Mureș, Romania. Tel:+400265 215551

\begin{abstract}
An uncomplicated, sensitive liquid chromatography linked to mass spectrometry (LC/MS) for evaluation of carbamazepine and carbamazepine-10,11-epoxide (its metabolite) in human plasma, human saliva, rat plasma, and rabbit plasma was developed. Analyses were conducted on a Zorbax SB-C18, $100 \mathrm{~mm} \times 3 \mathrm{~mm}$ ID, $3.5 \mu \mathrm{m}$ column, at a column temperature of $40{ }^{\circ} \mathrm{C}$. The mobile phase was comprised of $0.1 \%$ formic acid in water and methanol in a $35: 65(\mathrm{v} / \mathrm{v})$ ratio, with a flow rate of $0.4 \mathrm{~mL} / \mathrm{min}$. Lacosamide was utilized as internal standard. Under these chromatographic conditions, the retention times of lacosamide, carbamazepine-10,11-epoxide, and carbamazepine were $1.4 \mathrm{~min}, 1.6 \mathrm{~min}$, and $2.2 \mathrm{~min}$, respectively. The quantification of the analytes was performed using multiple reaction monitoring, with the use of a triple quadrupole mass spectrometer with electrospray positive ionization. The monitored ions were $\mathrm{m} / \mathrm{z} 194 \mathrm{de}$ rived from $\mathrm{m} / \mathrm{z} 237$ for carbamazepine, $\mathrm{m} / \mathrm{z} 180$ derived from $\mathrm{m} / \mathrm{z} 253$ for carbamazepine-10,11epoxide, and $\mathrm{m} / \mathrm{z} 108$ derived from $\mathrm{m} / \mathrm{z} 251$ for lacosamide. The samples were prepared by protein precipitation from $0.2 \mathrm{~mL}$ of plasma/saliva using $0.6 \mathrm{~mL}$ of internal standard solution in methanol. Calibration curves were constructed over the ranges $1.1-17.6 \mu \mathrm{g} / \mathrm{mL}$ and $0.23-5.47$ $\mu \mathrm{g} / \mathrm{mL}$ for carbamazepine and carbamazepine-epoxide, respectively. The coefficients of determination obtained by using a weighted $(1 / x)$ linear regression were greater than 0.994 . The reported LC-MS/MS method was applied to preclinical pharmacokinetic studies and therapeutic drug monitoring.
\end{abstract}

Keywords: carbamazepine, metabolite, LC-MS, therapeutic drug monitoring, pharmacokinetics

\section{INTRODUCTION}

Carbamazepine (CBZ) is a first-line therapy in different types of epileptic syndromes, also effective in bipolar and psychotic disorders and in neuropathic pain. ${ }^{1,2} \mathrm{CBZ}$ presents hepatic metabolization through the cytochrome $\mathrm{P} 450$ (CYP) pathway, into its pharmacological active form, carbamazepine-10,11-epoxide (CBZ-EP), which is then metabolized to an inactive trans-carbamazepine diol by epoxide hydrolase. ${ }^{3}$ 
Several pharmacokinetic interactions were identified between CBZ and other antiepileptic drugs (AEDs), due to CYP3A4 enzyme induction or inhibition, which leads to a decrease or increase of CBZ concentration in blood. ${ }^{4}$ Therapeutic drug monitoring (TDM) is strongly recommended for CBZ, and it is clearly defined when the level of CBZ rises above a specific level, which leads to toxic adverse reactions more frequently, especially in the elderly. Therapeutic levels of CBZ are $4-12 \mu \mathrm{g} / \mathrm{mL}$ $(17-51 \mu \mathrm{mol} / \mathrm{L})$, and above $20 \mu \mathrm{g} / \mathrm{mL}(84.6 \mu \mathrm{mol} / \mathrm{L})$ it is considered toxic. ${ }^{5}$

Another important issue is the role of CBZ-EP in toxic reactions: CBZ-EP is known to contribute to the pharmacodynamic action of CBZ, but levels higher than $8 \mu \mathrm{g} / \mathrm{mL}$ $(34 \mu \mathrm{mol} / \mathrm{L})$ are thought to be correlated with its own toxicity besides that of CBZ. 6,7

Therefore, simultaneous quantification of carbamazepine and CBZ-EP is demanded for studying the pharmacokinetics of this AED and for the dose adjustment of treated patients. ${ }^{8-11}$ However, some experts questioned the relevance of CBZ-EP assay for TDM. ${ }^{12,13}$

Although several attempts were made to replace the standard high-performance liquid chromatography (HPLC) methods with faster and simpler alternatives, there is a general consensus that TDM needs highly specific, robust, and validated methods for obtaining reliable results, the latter being essential in case of pharmacokinetic studies. ${ }^{13-15}$

Others proposed more convenient collection methods of biological samples in order to increase TDM feasibility. Dried blood-spot (DBS) was an innovative surrogate for classic blood sample collection, as highly specific tandem mass spectrometry detection enabled the determination of the analyte of interest from very small sample volumes. ${ }^{16}$ Where applicable, the use of saliva samples became a very popular TDM approach, particularly in pediatrics. ${ }^{17,18}$

Recently, a simple and cost-efficient analytic technique was proposed for the investigation of CBZ and CBZ-EP levels in rat plasma, which was validated and successfully used in a preclinical pharmacokinetic research study. ${ }^{19}$ However, a very similar method based on ultra performance liquid chromatography (UPLC) with UV-detection (UPLC-UV) was reported earlier for the quantification of the analytes in humans. ${ }^{20}$

Still, there is a need to improve the turnout of the aforementioned methods. Thus, in the present work, we proposed to further simplify the sample preparation procedures and increase the throughput of the chromatographic method by also reducing analysis time. Another important objective of this study was the elimination of the matrix effect and the application of the newly developed method to measure CBZ and CBZ-EP concentration levels in rat plasma, rabbit plasma, human plasma, and human saliva. To our best knowledge, this is the first method that involves protein precipitation as sample preparation method with an analytical run-time of $4 \mathrm{~min}$ utes. The procedure was successfully applied to a preclinical pharmacokinetic study in rats and rabbits and to TDM in epileptic patients.

\section{EXPERIMENTAL}

\section{Reagents}

Carbamazepine was granted by Vim Spectrum SRL (manufactured by Polpharma Pharmaceutical Works, Poland), carbamazepine-10,11-epoxide was purchased from SigmaAldrich. The solvents used were HPLC-grade acetonitrile, formic acid, and HPLC-grade methanol (Merck KgaA, Darmstadt, Germany). Ultrapure water was obtained with a Millipore Direct Q5 purification system (Millipore SAS, Molsheim, France). The blood center in Tîrgu Mureș, Romania provided the human plasma for blank, calibrator, and quality control samples.

\section{Standard solutions}

Stock solutions $(1.1 \mathrm{mg} / \mathrm{mL})$ of CBZ and CBZ-EP were processed by dissolving a suitable quantity of reference substance (measured with a Mettler-Toledo AB54-S analytical scale) in methanol. Lacosamide was dissolved in ultrapure water, yielding the stock solution of the internal standard $(1.1 \mathrm{mg} / \mathrm{mL})$. Six calibration working solutions ranging between $5.5-88 \mu \mathrm{g} / \mathrm{mL}$ for $\mathrm{CBZ}$ and $1.14-27.36 \mu \mathrm{g} / \mathrm{mL}$ for CBZ-EP were obtained by diluting specific volumes of stock solution with methanol. The internal standard working solution was prepared from the stock solution with methanol to a final concentration of $4.6 \mu \mathrm{g} / \mathrm{mL}$. Plasma calibration standards $(\mathrm{N}=6)$ in the concentration range of $1.1-17.6 \mu \mathrm{g} / \mathrm{ml}$ for CBZ and $0.23-5.47 \mu \mathrm{g} / \mathrm{mL}$ for CBZ-EP were prepared by spiking $0.12 \mathrm{~mL}$ of blank plasma with 40 $\mu \mathrm{L}$ of working solutions of CBZ and CBZ-EP, respectively.

\section{Liquid chromatography with mass spectrometry detection}

An Agilent 1100 series (Agilent Technologies, Santa Clara, CA, USA) HPLC system (equipped with in-line degasser, quaternary pump, thermostatted column compartment, 


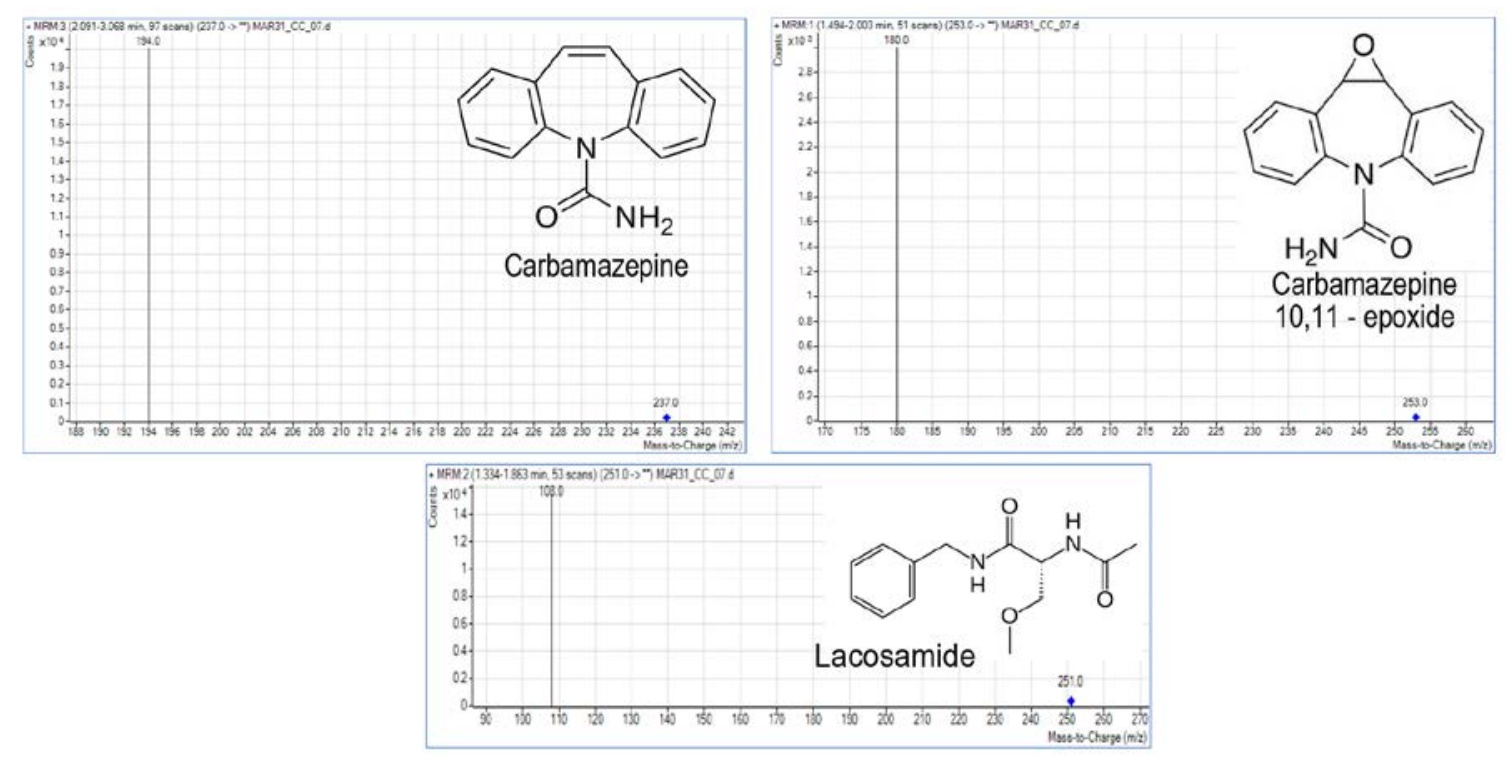

FIGURE 1. Monitored ions $(\mathrm{m} / \mathrm{z}$ ) of carbamazepine, carbamazepine-10,11-epoxide, and internal standard, lacosamide in mass spectrometer

and autosampler) was used for the laboratory determinations. The mass spectrometric detector was a Triple Quad G6410A model by Agilent Technologies together with the MassHunter software, which served for chromatogram acquisition and processing.

Positive electrospray ionization was chosen because of the higher intensities of the ions. The monitored ions were evaluated in multiple reaction monitoring (MRM) mode: $194 \mathrm{~m} / \mathrm{z}$ derived from $237 \mathrm{~m} / \mathrm{z}$ carbamazepine, collision energy $18 ; 180 \mathrm{~m} / z$ derived from $253 \mathrm{~m} / z$ carbamazepine epoxide, collision energy 10 ; and $108 \mathrm{~m} / \mathrm{z}$ derived from $251 \mathrm{~m} / z$ lacosamide, collision energy 4 (Figure 1). Other detector parameters included a dry heat of $350{ }^{\circ} \mathrm{C}$, nebulizer $40 \mathrm{psi}$, voltage $4,000 \mathrm{~V}$, dry gas (nitrogen) at a rate of $8 \mathrm{~L} / \mathrm{min}$.

Chromatographic separation was achieved at $40{ }^{\circ} \mathrm{C}$ on an in-line filter protected with Zorbax SB-C18 $100 \times 3$ $\mathrm{mm}, 3.5 \mu \mathrm{m}$ column (Agilent Technologies).

\section{Mobile phase}

The mobile phase was obtained by dissolving $0.1 \%$ formic acid in pure water and methanol in a 35:65 (v/v) ratio. For degassing, an ultrasonic bath (Clifton 64426) was used. The flow rate was set to $0.4 \mathrm{~mL} / \mathrm{min}$.

\section{Sample preparation}

Plasma and saliva samples underwent protein precipitation before analysis: $0.2 \mathrm{~mL}$ plasma/saliva was vortexed for 30 seconds with $0.6 \mathrm{~mL}$ working solution of lacosamide $4.6 \mu \mathrm{g} / \mathrm{mL}$ in methanol, then centrifuged for 10 minutes at 10,000 rpm. The supernatant was transferred into an autosampler vial and $2 \mu \mathrm{L}$ were injected into the LC-MS system.

\section{Method parameter verification}

Different blank matrices: human saliva, human plasma, rat plasma, and rabbit plasma were used for verifying specificity.

The external standard calibration method was used for linearity, where the least squares analysis defined the calibration curve model. A $1 / x$ weighted linear calibration was applied: $y=a x+b(x-$ concentration ratio, $y$ - peak area ratio). The lowest calibration standard with an accuracy and precision of less than $20 \%$ was set to be the lower limit of quantification (LLOQ).

By comparing the responses of analytes in solution and prepared spiked plasma standards with the same concentration, a relative recovery was calculated.

\section{RESULTS AND DISCUSSION}

Representative MRM chromatograms of human blank plasma and blank plasma spiked with $\mathrm{CBZ}(\mathrm{RT}=2.2 \mathrm{~min})$ and CBZ-EP $(\mathrm{RT}=1.6 \mathrm{~min})$ at LLOQ $(\mathrm{CBZ} 1.1 \mu \mathrm{g} / \mathrm{mL}$, CBZ-EP $0.23 \mu \mathrm{g} / \mathrm{mL}$ ) demonstrated the selectivity of the method (Figure 2). The chromatograms showed that there was no interference at the retention times of the analytes 
(a)

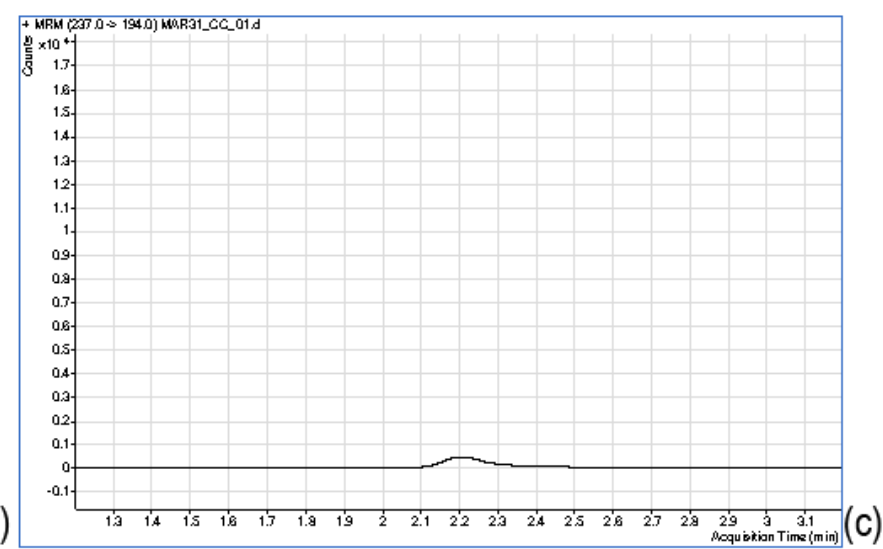

(b)

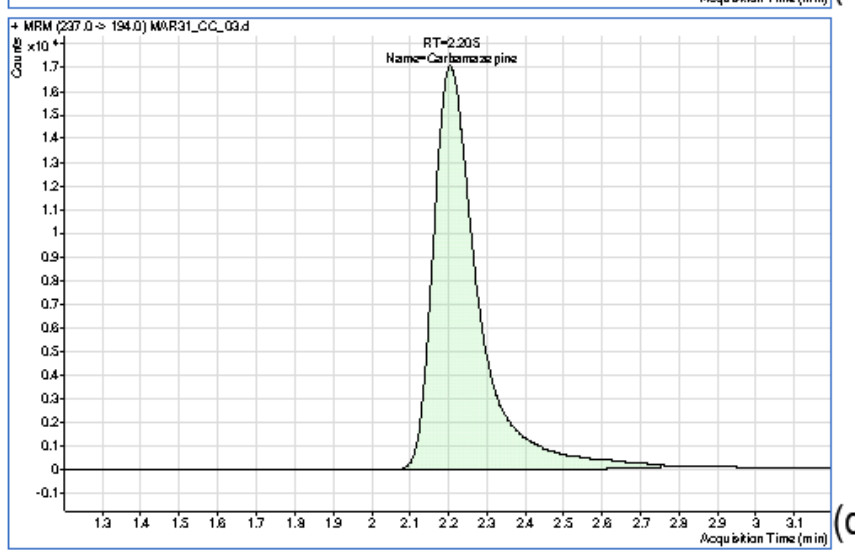

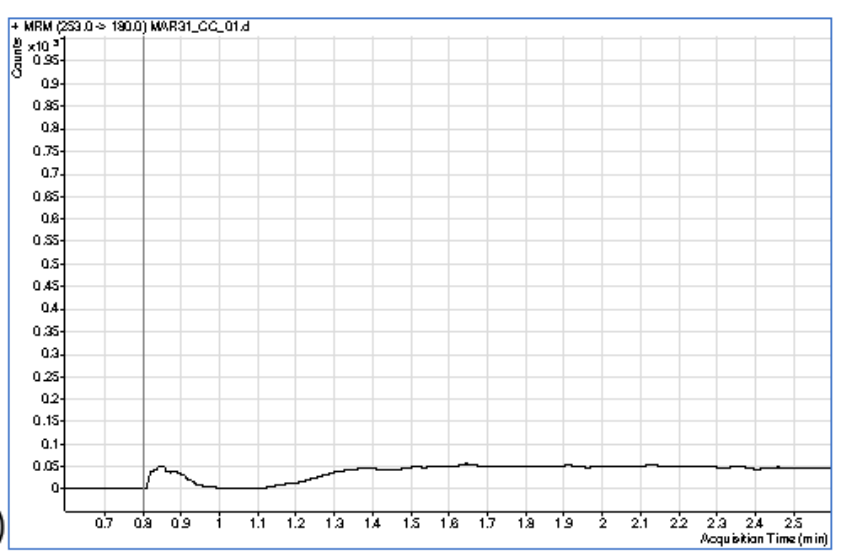

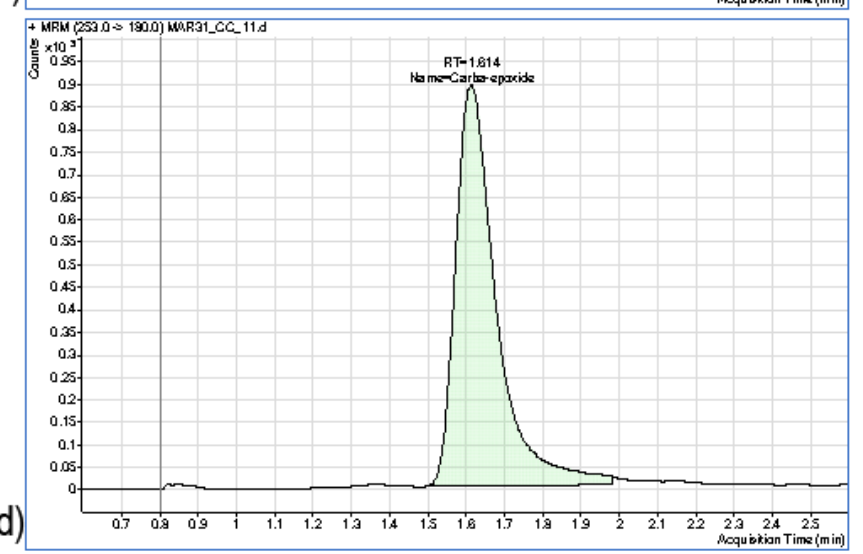

FIGURE 2. Multiple reaction monitoring (MRM) chromatograms of a blank (a, c) and a spiked human plasma sample at LLOQ carbamazepine: $1.1 \mu \mathrm{g} / \mathrm{mL}$, carbamazepine-10,11-epoxide: $0.23 \mu \mathrm{g} / \mathrm{mL}(\mathrm{b}, \mathrm{d})$; retention times: $1.6 \mathrm{~min}$ CBZ-EP (c, d); $2.2 \mathrm{~min}$ CBZ (a, b)

and lacosamide (IS). Under the chromatographic conditions described above, peaks were adequately separated, and the observed retention times were $2.2 \mathrm{~min}, 1.6 \mathrm{~min}$, and $1.4 \mathrm{~min}$ for CBZ, CBZ-EP, and IS, respectively.

The selectivity of the technique was evaluated by using different batches of blank human plasma, human saliva, rat plasma, and rabbit plasma.

As protein precipitation has the advantages of speed and simplicity, our initial approach during method development was based on precipitation of plasma proteins with acetonitrile and methanol. The extracts gave nonsignificant matrix interference and good recovery for the analytes ( $>90 \%$ for CBZ) and IS (Table 1). Thus, protein precipitation was adopted.

The lower limit of measurement was set at $1.1 \mu \mathrm{g} / \mathrm{mL}$ for CBZ and $0.23 \mu \mathrm{g} / \mathrm{mL}$ for CBZ-EP. Due to a good sensitivity achieved with the triple quadrupole mass spectrometer, it was possible to improve other important parameters of the bioanalytical methods, obtaining better or equal results than in the previously published LC-MS methods for the simultaneous analysis of CBZ and CBZ-EP from any biological sample (Table 2).
The carryover was determined by injection of blank samples right after a standard sample corresponding to the upper limit of quantification. There was no observed interference at the retention time of the analytes.

Correlation between the peak area ratios and their corresponding concentrations was described best with the mean linear regression equations $\mathrm{y}=\mathrm{ax}+\mathrm{b}$, where $\mathrm{y}$ $=0.68 \mathrm{x}+0.10(\mathrm{~N}=6)$ for CBZ and $\mathrm{y}=0.24 \mathrm{x}-8.10^{-4}$ $(\mathrm{N}=6)$ for CBZ-EP. The calibration curves were adequate in the range of $1.1-17.6 \mu \mathrm{g} / \mathrm{mL}$ for CBZ and $0.23-5.47 \mu \mathrm{g} /$ $\mathrm{mL}$ for CBZ-EP, with coefficient of determinations $\left(\mathrm{r}^{2}\right)$ greater than 0.994; the residuals did not show any trend.

TABLE 1. Recovery of carbamazepine from plasma samples

\begin{tabular}{lcc}
\hline Replicate & Rec $\mathbf{A}$ & $\boldsymbol{R e c} \mathbf{C}$ \\
\hline Nominal & $1.32 \mu \mathrm{g} / \mathrm{mL}$ & $11 \mu \mathrm{g} / \mathrm{mL}$ \\
Area Rec & $2.95 \times 10^{3}$ & $1.90 \times 10^{4}$ \\
Area QC & $2.46 \times 10^{3}$ & $1.93 \times 10^{4}$ \\
\% recovery & 83.5 & 101.5 \\
Mean recovery & & 92.5 \\
\hline
\end{tabular}


TABLE 2. Comparison of characteristics of the present technique with reported methods for carbamazepine and its main metabolite, 10,11-epoxide-carbamazepine, in biological fluids

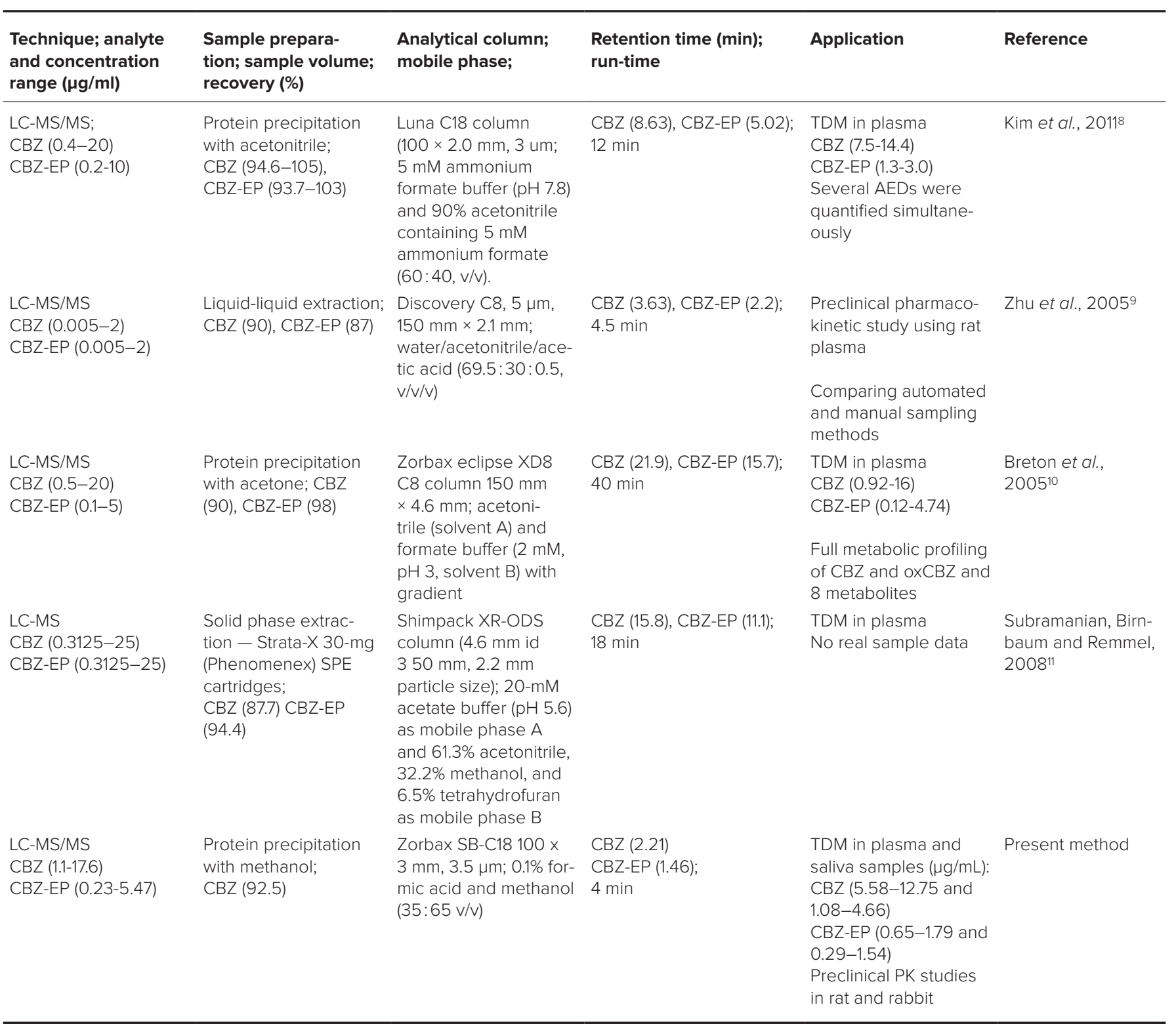

\section{Application of the method and pharmacokinetic (PK) results}

\section{Preclinical PK study}

A pilot PK study was performed in rabbits and rats, in order to monitor the interspecies differences related to the metabolism of CBZ. For this purpose, the plasma concentrations of CBZ and CBZ-EP were determined in different time-points, and the concentration-time curves were obtained. In rabbits, the $\mathrm{t}_{\max }$ of $\mathrm{CBZ}$ was $2 \mathrm{~h}$ and that of CBZ-EP was $8 \mathrm{~h}$ (Figure 3), reflecting a slower biotransformation of the drug in rabbits compared to rats.

\section{Therapeutic drug monitoring}

The plasma concentration of CBZ was analyzed in five epileptic patients in order to monitor the therapy. Blood samples were collected at $\mathrm{C}_{\min }$ (trough concentration) and $\mathrm{C}_{\max }$ (peak concentration). All patients had their CBZ plasma levels in the therapeutic range (Figure 4a). The plasma concentration of CBZ-EP ranged between $0.65-1.79 \mu \mathrm{g} / \mathrm{mL}$, far from the toxic level of $8 \mu \mathrm{g} / \mathrm{mL}$ (Figure 4b). In parallel with blood collection, saliva samples were also collected from the same patient (Figure 5). Salivary CBZ and CBZ-EP levels trailed the blood concentrations, the mean ratio of saliva-to-plasma concentration was 0.25 for $\mathrm{CBZ}$ and 0.55 for CBZ-EP, with an 


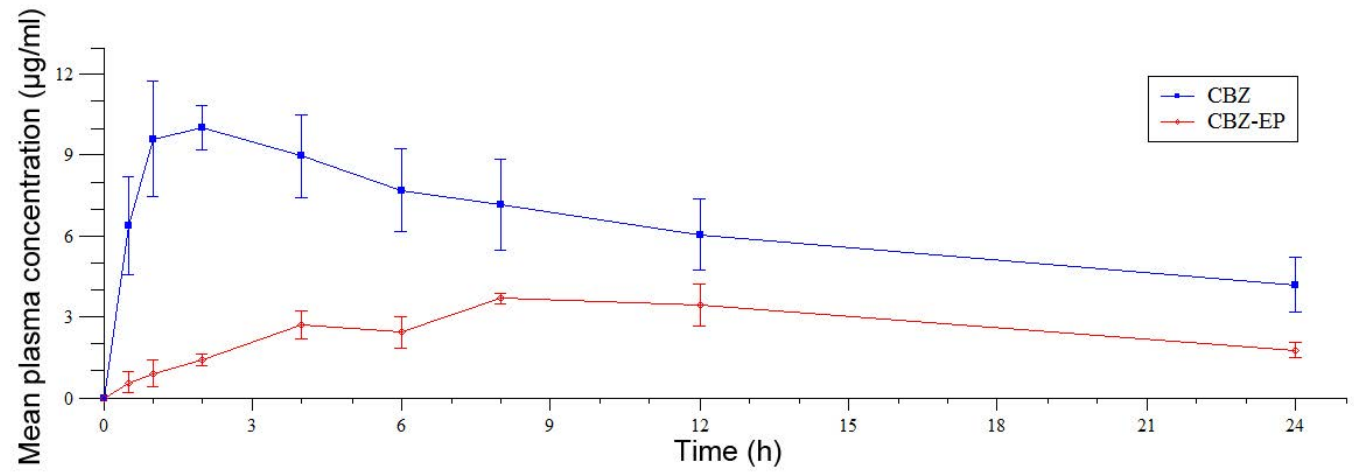

FIGURE 3. Mean plasma concentration ( $\mu \mathrm{g} / \mathrm{mL}$ ) versus time (hour) plot of carbamazepine (blue curve) and carbamazepine-10,11-epoxide (red curve) in rabbits ( $\mathrm{N}=6$ ) after oral administration of $100 \mathrm{mg} / \mathrm{kg}$ carbamazepine
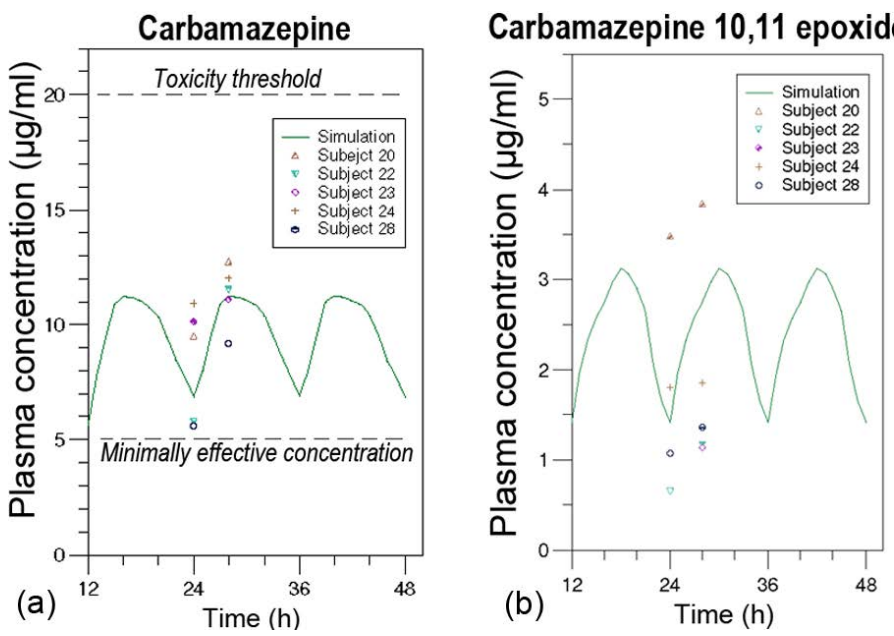

FIGURE 4. Plasma concentration $(\mu \mathrm{g} / \mathrm{mL}$ ) versus time (hour) curves of carbamazepine (a) and carbamazepine-10,11-epoxide (b) in epileptic patients $(\mathrm{N}=5)$ at steady state

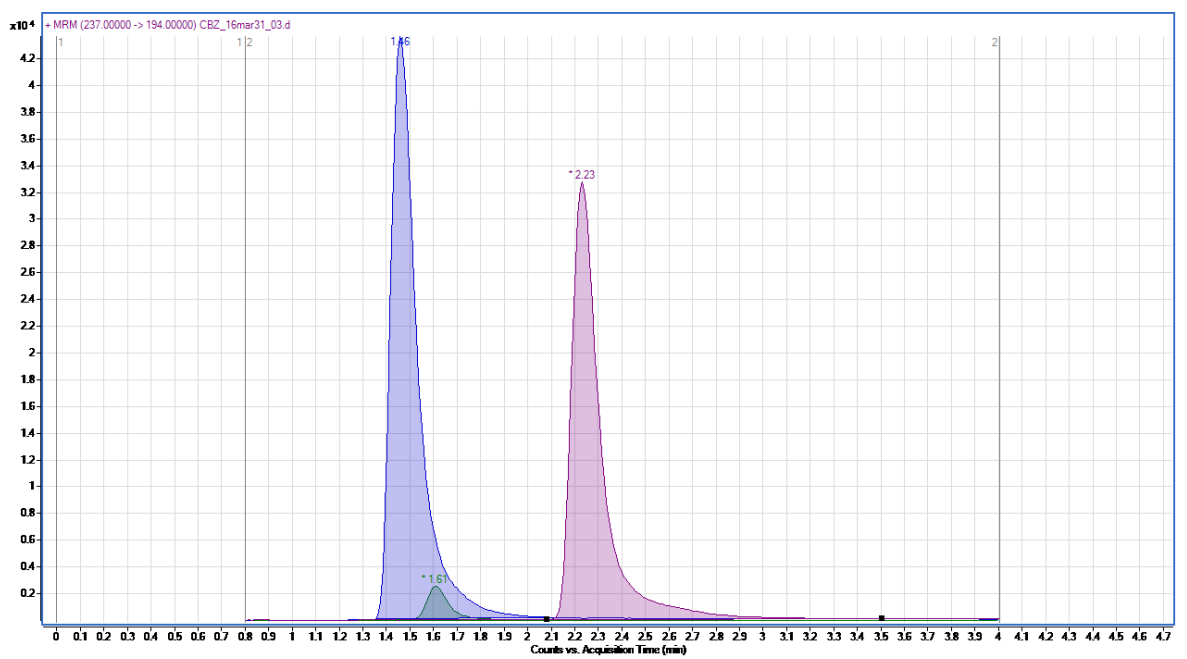

FIGURE 5. Representative overlaid multiple reaction monitoring (MRM) chromatograms of a human saliva sample. Retention times were $1.4 \mathrm{~min}, 1.6 \mathrm{~min}$, and $2.2 \mathrm{~min}$ for IS (lacosamide), CBZ-EP, and CBZ, respectively. 
TABLE 3. Carbamazepine and carbamazepine-10,11 epoxide concentrations $(\mu \mathrm{g} / \mathrm{mL})$ in saliva of epileptic patients at steady state $\left(C_{\text {min }}\right.$ before the following dose, $C_{\max }$ after 4 hours of administered dose)

\begin{tabular}{|c|c|c|c|c|c|c|c|c|}
\hline Subject no. & \multicolumn{2}{|c|}{ Saliva } & \multicolumn{2}{|c|}{ Saliva-to-plasma ratio } & \multicolumn{2}{|c|}{ Saliva } & \multicolumn{2}{|c|}{ Saliva-to-plasma ratio } \\
\hline 20 & 3.48 & 3.84 & 0.366 & 0.302 & 1.28 & 1.54 & 0.888 & 0.859 \\
\hline 22 & 1.59 & 2.78 & 0.275 & 0.241 & 0.29 & 0.53 & 0.449 & 0.456 \\
\hline 24 & 1.75 & 2.87 & 0.160 & 0.239 & 0.55 & 0.77 & 0.304 & 0.417 \\
\hline 28 & 1.73 & 1.08 & 0.311 & 0.119 & 0.86 & 0.46 & 0.796 & 0.337 \\
\hline Mean & 1.94 & 3.05 & 0.25 & 0.26 & 0.66 & 0.87 & 0.55 & 0.60 \\
\hline SD & 0.89 & 1.34 & 0.10 & 0.11 & 0.37 & 0.40 & 0.25 & 0.25 \\
\hline CV\% & 46 & 44 & 43 & 41 & 56 & 45 & 45 & 41 \\
\hline
\end{tabular}

inter-individual coefficient of variation (CV\%) larger than $40 \%$ (Table 3 ).

The presented analytical method has high sensitivity and adequate reproducibility; however, the utilization of saliva as a surrogate for therapeutic drug monitoring should be carefully evaluated in relation to standardization of preanalytical variables such as accurate choice of sampling methods, direct volume quantification, and prevention of sample contamination with blood and food debris. ${ }^{21}$

\section{CONCLUSIONS}

The present method offers adequate sensitivity, proper accuracy, and precision for simultaneous determination of CBZ and CBZ-EP in humans and different laboratory animal species (rat and rabbit) by using plasma and/or saliva samples.

The sample preparation by protein precipitation is simpler, it requires smaller amounts of organic solvent and a small sample quantity, but provides a good recovery of the analytes without additional steps (extraction or derivatization).

The simplicity of sample preparation, relatively short run time, and the selectivity of the signals used for analysis permitted a specific and effective analysis of plasma and saliva probes, thus being a cost-effective method. The developed method was used for therapeutic drug monitoring of carbamazepine and carbamazepine-epoxide, but it is also capable to accurately measure their concentration in clinical or preclinical pharmacokinetic studies.

\section{CONFLICT OF INTEREST}

Nothing to declare.

\section{ACKNOWLEDGEMENT}

The work was supported by the joint project of the Studium Prospero Foundation and the Hungarian Academy of Sciences.

\section{REFERENCES}

1. Ettinger AB, Argoff CE. Use of Antiepileptic Drugs for Nonepileptic Conditions: Psychiatric Disorders and Chronic Pain. Neurotherapeutics. 2007:4:75-83.

2. Brodie MJ. Antiepileptic drug therapy the story so far. Seizure. 2010;19:650655

3. Kerr BM, Thummel KE, Wurden CJ, et al. Human liver carbamazepine metabolism. Biochem Pharmacol. 1994;47:1969-1979.

4. Johannessen SI, Landmark CJ. Antiepileptic drug interactions - principles and clinical implications. Curr Neuropharmacol. 2010;8:254-267.

5. Patsalos PN, Berry DJ, Bourgeois BFD, et al. Antiepileptic drugs - Best practice guidelines for therapeutic drug monitoring: A position paper by the subcommission on therapeutic drug monitoring, ILAE Commission on Therapeutic Strategies. Epilepsia. 2008;49:1239-1276.

6. Johannessen SI, Battino D, Berry DJ, et al. Therapeutic drug monitoring of the newer antiepileptic drugs. Ther Drug Monit. 2003;25:347-363.

7. Neels HM, Sierens AC, Naelaerts K, Scharpé SL, Hatfield GM, Lambert WE. Therapeutic drug monitoring of old and newer anti-epileptic drugs. Vol. 42, Clinical Chemistry and Laboratory Medicine; 2004. p. 1228-1255.

8. Kim K-B, Seo K-A, Kim S-E, Bae SK, Kim D-H, Shin J-G. Simple and accurate quantitative analysis of ten antiepileptic drugs in human plasma by liquid chromatography/tandem mass spectrometry. J Pharm Biomed Anal. 2011;56:771-777.

9. Zhu $\mathrm{Y}$, Chiang $\mathrm{H}$, Wulster-Radcliffe $\mathrm{M}$, et al. Liquid chromatography/ tandem mass spectrometry for the determination of carbamazepine and its main metabolite in rat plasma utilizing an automated blood sampling system. J Pharm Biomed Anal. 2005;38:119-125.

10. Breton H, Cociglio M, Bressolle F, Peyriere H, Blayac JP, Hillaire-Buys D. Liquid chromatography-electrospray mass spectrometry determination of carbamazepine, oxcarbazepine and eight of their metabolites in human plasma. J Chromatogr B Anal Technol Biomed Life Sci. 2005;828:80-90.

11. Subramanian M, Birnbaum AK, Remmel RP. High-Speed Simultaneous Determination of Nine Antiepileptic Drugs Using Liquid ChromatographyMass Spectrometry. Ther Drug Monit. 2008;30:347-356.

12. Theodore WH, Narang PK, Holmes MD, Reeves P, Nice FJ. Carbamazepine and its epoxide: Relation of plasma levels to toxicity and seizure control. Ann Neurol. 1989;25:194-196.

13. Burianová I, Bořecká K. Routine therapeutic monitoring of the active metabolite of carbamazepine: Is it really necessary? Clin Biochem. 2015;48:866-869 
14. Krasniqi S, Zeitlinger M, Bauer S. Comparison between the immunoassay and high performance liquid chromatography for therapeutic monitoring of carbamazepine and phenytoine. Biochem Medica. 2010;341-349.

15. Ferreira A, Rodrigues $M$, Oliveira $P$, et al. Liquid chromatographic assay based on microextraction by packed sorbent for therapeutic drug monitoring of carbamazepine, lamotrigine, oxcarbazepine, phenobarbital, phenytoin and the active metabolites carbamazepine-10,11-epoxide and licarbazepine. J Chromatogr B Anal Technol Biomed Life Sci. 2014;971:2029.

16. Shokry E, Villanelli F, Malvagia S, et al. Therapeutic drug monitoring of carbamazepine and its metabolite in children from dried blood spots using liquid chromatography and tandem mass spectrometry. J Pharm Biomed Anal. 2015;109:164-170.

17. Đorđević $S$, Kilibarda $V$, Stojanović T. Determination of carbamazepine in serum and saliva samples by high performance liquid chromatography with ultraviolet detection Odre đ ivanje karbamazepina u uzorcima seruma i salive primenom te č ne hromatografije visokih performansi sa ultravioletnom de. Vojn Pregl. 2009;66:347-352.

18. Krasowski MD, McMillin GA. Advances in anti-epileptic drug testing. Clin Chim Acta. 2014;436:224-236

19. Beig A, Dahan A. Quantification of carbamazepine and its 10,11-epoxide metabolite in rat plasma by UPLC-UV and application to pharmacokinetic study. Biomed Chromatogr. 2014;28:934-938.

20. Ates Z, Oezden T, Oezilhan S, Toptan S. Simultaneous determination of carbamazepine and its active metabolite carbamazepine-10,11-epoxide in human plasma by UPLC. Chromatographia. 2007;66:S123-S127.

21. Nunes LAS, Mussavira S, Bindhu OS. Clinical and diagnostic utility of saliva as a non-invasive diagnostic fluid: a systematic review. Biochem Med (Zagreb). 2015;25:177-192. 